\title{
EXERGY ANALYSIS AND IGCC PLANT TECHNOLOGY TO IMPROVE THE EFFICIENCY AND TO REDUCE THE EMISSION IN THERMAL POWER PLANT- A REVIEW
}

\author{
Adithya Rao ${ }^{1}$, Anish S ${ }^{2}$, Chirag Raj ${ }^{3}$, Vijaykumar. G. Tile ${ }^{4}$ \\ ${ }^{I}$ Student, Department of Mechanical Engineering, Malnad College of Engineering Hassan, Karnataka, India \\ ${ }^{2}$ Student, Department of Mechanical Engineering, Malnad College of Engineering Hassan, Karnataka, India \\ ${ }^{3}$ Student, Department of Mechanical Engineering, Malnad College of Engineering Hassan, Karnataka, India \\ ${ }^{4}$ Professor, Department of Mechanical Engineering, Malnad College of Engineering Hassan, Karnataka, India
}

\begin{abstract}
Thermal power plants convert energy rich fuel into electricity and heat. Possible fuels include coal, natural gas, petroleum products, agricultural waste and domestic trash / waste. Other sources of fuel include landfill gas and biogases. In some plants, renewal fuels such as biogas are co-fired with coal. Coal and lignite accounted for about $57 \%$ of India's installed capacity. India's electricity sector consumes about $80 \%$ of the coal produced in the country. India expects that its projected rapid growth in electricity generation over the next couple of decades is expected to be largely met by thermal power plants. But the present thermal power plants which are in India will not be able to meet the future demands and also it is been observed by our internship in one of the thermal power plant in Karnataka.
\end{abstract}

This paper presents a review of the methodology to evaluate the performance of the coal based power plants using exergy as the main criterion and the objectives of this paper is to overview the technology development of Integrated gasification combined cycle (IGCC) power plant included the advantages and disadvantages of IGCC power plant. Our interest is to explore and implement the recent research in these fields in India and to empower the country by increased production rate of electricity mean while the concern should be taken on impacts of pollutants on the environment and globe. Here both exergy analysis and IGCC plant technology are discussed separately in two sections, which will give brief review about both.

Most of the power plants are designed by the energetic performance criteria based not only on the first law of thermodynamics, but the real useful energy loss cannot be justified by the fist law of thermodynamics, because it does not differentiate between the quality and quantity of energy. The present study deals with the comparison of energy and exergy analysis of thermal power plants stimulated by coal and Integrated Gasification Combined Cycle (IGCC) is emerging as a best available technology to utilize low quality or contaminated energy resources, coal or oil. It can meet emission limits not achievable by other conventional or advanced competing technologies. In particular IGCC offers refiners the possibility of reducing to zero the production of residual fuel oil, an increasingly undesired product, while at the same time, co-producing electricity, hydrogen and steam. It also drastically cuts SO2 emissions.

Keywords: Thermal Power Plant, Exergy, Energy utilization, Irreversibility, CPP, IGCC, CCS

\section{EXERGY ANALYSIS}

\subsection{Introduction}

Energy consumption is one of the most important problems in front of any developing countries. India is not an exception for this. In the current scenario per capita energy consumption determines the level of development of the nation. By understanding that the world's energy resources are limited, many countries have reevaluated their energy policies and are taking measures for eliminating the waste. It has also developed the interest in the scientists and researchers to take a close look at the energy conversion devices and to develop new techniques for better usage of the available resources.

The First Law of Thermodynamics deals with the amounts of energy of various forms transferred between the system and its surroundings and with the changes in the energy stored in the system. It treats work and heat interactions as equivalent forms of energy in transit and offers no indication about the possibility of a spontaneous process proceeding in a certain direction. The first law places no restriction on the direction of a process, but satisfying the first law does not ensure that the process can actually occur. This inadequacy of the first law to identify whether a process can take place is remedied by 
introducing another general principle of second law of thermo dynamics.

The method of exergy analysis is based on second law of thermodynamics and the concept of irreversible production of entropy. The fundamentals of the exergy method were laid down by Carnot in 1824 and Clausius in 1865 . The energyrelated engineering systems are designed and their performance is evaluated primarily by using the energy balance deduced from the First law of thermodynamics. Engineers and scientists have been traditionally applying the First law of thermodynamics to calculate the enthalpy balances for more than a century to quantify the loss of efficiency in a process due to the loss of energy. The exergy concept has gained considerable interest in the thermodynamic analysis of thermal processes and plant systems since it has been seen that the First law analysis has been insufficient from an energy performance stand point.

Keeping in view the facts discussed above, it can be expected that performing an analysis based on the same definition of performance criteria will be meaningful for performance comparisons, assessments and improvement for thermal power plants. Additionally, considering both the energetic and exergetic performance criteria together can guide the ways of efficient and effective usage of fuel resources by taking into account the quality and quantity of the energy used in the generation of electric power in thermal power plants. The purpose of this study presented here is to carry out energetic and exergetic performance analyses, at the design conditions, for the existing coal and gas-fired thermal power plants in order to identify the needed improvement. For performing this aim, we summarized thermodynamic models for the considered power plants on the basis of mass, energy and exergy balance equations. The thermodynamic model simulation results are compared. In the direction of the comprehensive analysis results, the requirements

\subsection{Energy and Exergy Analysis of Coal Fired Cogeneration Power Plant with Condensate}

\section{Extraction Turbine}

\subsubsection{Energy Analysis of Coal Fired Cogeneration}

\section{Power Plant with Condensate Extraction Turbine.}

In general coal based thermal plant works on Rankin cycle. Several advancement has made in recent thermal power plant to increase the energy output per unite mass of fuel burnt like reheating, regeneration etc. The design of any power plant is based on location, availability of fuel and it effectiveness. Since thermal power plant works on fossil fuel, it has made great interest to research to look for more efficient utilization of this fuel due to its stock limitation under earth. Which results into no. of analysis based on energy losses and irreversibility, various attempts were made to overcome this loss as and hence reheat cycle, regenerative cycle are the some very useful outcome that came out for improvement.

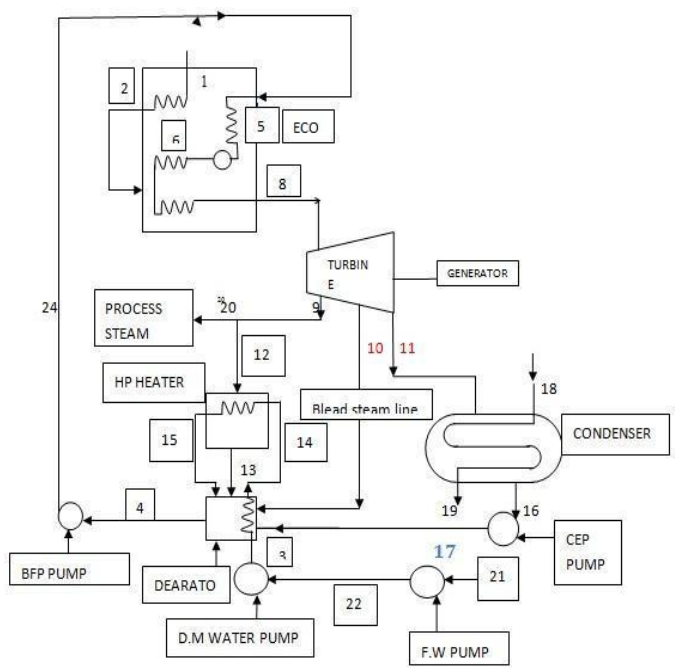

Fig 1: Block diagram of thermal power plant

Fig 1 shows the detail part of cogeneration coal based with condensate extraction turbine consists of Boiler (B), Condensate extraction turbine with three stages (T) Pump (P), Dearator (D), a generator (S), condenser(c), high pressure feed water heater (HPH). The thermodynamic model of power plant which is displayed here is based on fundamental mass and energy balances. Using the energy and mass balance equation for each component in the power plant model, it is possible to compute energy and energy contents in terms of turbine power outputs pump power consumptions boiler flow. For minimized the loss of dry flue gas.

\subsection{Exergy Analysis Taking a 6 MW CPP as Case}

\section{Study}

Useful work potential of a system is the amount of the energy we extract as useful work. The useful work potential of a system at the specified state is called exergy. Exergy is a property and is associated with the state of the system and the environment. A system that is in equilibrium with its surroundings has zero exergy and is said to be at the dead state. It means available energy at a specified condition. For the analysis purpose we have taken 6MW CPP for case study. Exergy analysis of boiler can be calculated by following formula which can be taken from research paper.

(1) Exergy analysis of fuel

(2) Exergy analysis of water

(3) Exergy analysis of air

(4) Exergy analysis of flue gas

(5) Exergy analysis of economizer

(6) Exergy analysis of steam drum

(7) Exergy analysis of super heater 


\subsubsection{Exergy Analysis of Fuel}

Exergy of fuel can be obtained or calculated by the equation proposes by shieh and fan for calculating the exergy of fuel Exergy of fuel can be calculated by using a shieh and fan formula

\section{$G_{\mathrm{f}}=34183016(\mathrm{C})+21.95(\mathrm{~N})+11659.9(\mathrm{H})+18242.90(\mathrm{~S})+13265$ 90(O)}

According to the T.J kotas say that the ratio of exergy of fuel to caloric value of the fuel lies between the 1.15 to 1.30 According to the our ultimate analysis we get exergy of the fuel is $=17683.84 \mathrm{KJ} / \mathrm{kg}$ and calorific value is $17585.4 \mathrm{KJ} / \mathrm{kg}$ thus ratio we get is 1.01 that is nearer to T.J kotas ratio.

Table 1.3 (a)

\begin{tabular}{|l|l|l|}
\hline Coal consituents & Unit & Coal Sample \\
\hline $\mathrm{C}$ & $\%$ & 45 \\
\hline $\mathrm{H}$ & $\%$ & 13 \\
\hline $\mathrm{N}$ & $\%$ & 1.69 \\
\hline $\mathrm{O}$ & $\%$ & 4.5 \\
\hline $\mathrm{S}$ & $\%$ & 0.5 \\
\hline Ash & $\%$ & 29.31 \\
\hline Moisture & $\%$ & 9.82 \\
\hline $\begin{array}{l}\text { Volatile } \\
\text { Matter }\end{array}$ & $\%$ & 20.16 \\
\hline Fixed Carbon & $\%$ & 34.71 \\
\hline Colorific Value & $\mathrm{Kcal} / \mathrm{Kg}$ & 4187 \\
\hline
\end{tabular}

Table 1.3 (b)

\begin{tabular}{|l|l|}
\hline Load in MW & Exergy of fuel in KW \\
\hline 5.6 & 32596.79 \\
\hline 5.4 & 31480.92 \\
\hline 4.9 & 30598.77 \\
\hline 3.7 & 27927.78 \\
\hline 1.1 & 13303.81 \\
\hline
\end{tabular}

\section{Discussion}

Table 1.3 (a) shows a clear details about the calorific value of coal and table 1.3(b) shows as load increases the exergy of fuel is also increases. So we can say by results that always run the plant in peak load

\subsubsection{The Exergy of Feed Water}

Before passing the water into the economizer, the water is allowed to get heated in the dearator thus the temperature of feed water is raised to higher temperature. The temperature water at economizer inlet will be given, Exergy of feed water can be calculated by

$$
E=\left(C_{P_{w}}\right)\left(T_{4}-T_{a}\right)-T_{a} \ln \left(T_{4} / T_{a}\right)
$$

$\mathbf{C}_{\mathbf{P}_{\mathrm{w}}}=$ calorific value of water $=4.187 \mathrm{KJ} / \mathrm{Kg}$

$\mathbf{T}_{4}=$ Temperature of feed water

$\mathbf{T}_{\mathrm{a}}=$ Ambient temperature

Table 1.3 (c)

\begin{tabular}{|l|l|}
\hline Load in MW & Exergy of water in KW \\
\hline 5.6 & 738.78 \\
\hline 5.4 & 749.38 \\
\hline 4.9 & 656.74 \\
\hline 3.7 & 565.12 \\
\hline 1.1 & 74.30 \\
\hline
\end{tabular}

By observing Table 1.3(c), it clearly indicates as load increases the exergy of water is also increases. So we can decide that always run the plant in peak load

\subsubsection{The Exergy of Air}

The exergy of air can be calculated by following formula

$$
\epsilon_{\mathrm{a}}=\left(\mathrm{C}_{\mathrm{Pa}}\right)\left(T_{2}-T_{\mathrm{a}}\right)-T_{\mathrm{a}} \ln \left(T_{2} / T_{\mathrm{a}}\right)
$$

Where,

$\mathrm{T}_{2}=$ Temperature of air after reheater

$\mathrm{T}_{\mathrm{a}}=$ Ambient Temperature

Table $1.3(d)$

\begin{tabular}{|l|l|}
\hline Load in MW & Exergy of Air in KW \\
\hline 5.6 & 115.08 \\
\hline 5.4 & 127.08 \\
\hline 4.9 & 139.21 \\
\hline 3.7 & 159.93 \\
\hline 1.1 & 32.77 \\
\hline
\end{tabular}

The exergy of air is depend upon the combustion air temperature as well as flue gas temperature, Due to that and from Table 1.3 (d) it is found that exergy at full load i.e. 5.6 MW is less as compared to the $3.7 \mathrm{MW}$, so the combustion air temp as well as flue gas temp should be properly maintained.

\subsubsection{The Exergy of Economizer}

The water entering the economizer from dearator is already at higher temp is then heated almost saturated temp at that pressure but leaving the economizer remain in liquid without change in phase

$$
€ \mathbf{a}=(c p w)(T 5-T 4)-T 4 \operatorname{Ln}(\mathrm{T5} / T 4)
$$

$\mathrm{T} 5$ and $\mathrm{T} 4$ are the temperatures of economizers at inlet and outlet

It is been observed as load increase exergy also increases. 


\subsubsection{The Exergy of Drum:-}

$$
\epsilon_{\text {drum }}=\left(\mathrm{h}_{6}-h_{5}\right)-T_{6}\left(\mathrm{~S}_{6}-\mathrm{S}_{5}\right)
$$

$\mathrm{T}_{6}=$ temperature of drum

Table $1.3(e)$

\begin{tabular}{|l|l|}
\hline Load in MW & Exergy of Drum \\
\hline 5.6 & 5123.37 \\
\hline 5.4 & 5196.87 \\
\hline 4.9 & 4742.20 \\
\hline 3.7 & 3989.80 \\
\hline 1.1 & 1408.98 \\
\hline
\end{tabular}

As Table 1.3 (e) shows that load increase exergy of drum is also increase but in some case exergy is reduced due to steam flow is reduced as it depends upon the extraction steam or process steam.

\subsubsection{The Exergy of Super Heater}

Super heater is placed at end of boiler mounting, and water passes after super heater, super heated steam is produced. The super heater for a given boiler is made up of three different component of super heater, primary super heater is rise the temp by extracting the heat from flue gas is called as convective super heater, and secondary super heater is exposed to the flame to which heat is done by radiation thus caused radiating super heater ,temp rang for the turbine inlet is fix if the steam temp is rises above the rang it is found that attemptator or spray control valve is open ,after that steam goes to the bed super heater

Exergy rise in the super heater $=\left(h_{8}-h_{6}\right)-T_{8}\left(S_{8}-S_{6}\right)$

Table 1.3(f)

\begin{tabular}{|l|l|}
\hline Load in MW & Exergy of super heater \\
\hline 5.6 & 2399.18 \\
\hline 5.4 & 2103.43 \\
\hline 4.9 & 2224.76 \\
\hline 3.7 & 1456.16 \\
\hline 1.1 & 669.21 \\
\hline
\end{tabular}

As per reading table 1.3(f) it is found that as load increase exergy rise of super heater also increase; it is depend upon the temp of drum as well as temp of super heater temp.

\subsubsection{The Exergy of Flue Gas}

$$
€ \mathrm{a}=(c p g)(T g-T a)-T a \operatorname{Ln}(T g / T a)
$$

Table 1.3 (g)

\begin{tabular}{|l|l|}
\hline Load in MW & Exergy of Flue gas \\
\hline 5.6 & 194.14 \\
\hline 5.4 & 200.23 \\
\hline 4.9 & 263.25 \\
\hline 3.7 & 220.32 \\
\hline 1.1 & 163.797 \\
\hline
\end{tabular}

From Table $1.3(\mathrm{~g})$ it is clear that as load increase exergy of flue gas increase, but it is again depend upon the temp of flue gas and boiler load if at particular load temp is less and boiler load is less then also exergy of flue gas is less.

\subsubsection{Total Exergy Gain by the Steam}

Table 1.3 (h)

\begin{tabular}{|l|l|}
\hline Load in MW & Total exergy gain by Steam \\
\hline 5.6 & 7711.21 \\
\hline 5.4 & 7491.68 \\
\hline 4.9 & 7203.08 \\
\hline 3.7 & 5606.04 \\
\hline 1.1 & 2215.74 \\
\hline
\end{tabular}

As load increase total exergy of drum gain by the steam increase from table $1.3(\mathrm{~h})$, it is sum of exergy rise in economizer and super heater

\subsubsection{Efficiency of Boiler}

Efficiency of boiler = Ratio of Total energy leaving the boiler to total energy entering the boiler

Table $1.3(\mathrm{~g})$

\begin{tabular}{|l|l|}
\hline Load in MW & Efficiency of boiler as per $2^{\text {nd }}$ law \\
\hline 5.6 & 23.67 \\
\hline 5.4 & 23.79 \\
\hline 4.9 & 23.54 \\
\hline 3.7 & 20.07 \\
\hline 1.1 & 16.65 \\
\hline
\end{tabular}

Table $1.3(\mathrm{~g})$ shows as load increases efficiency of boiler also increases

\section{RESULT AND DISCUSSION}

It is the discussion about the results what we have observed from various research papers and research works. Here in this case lot of precaution already taken for reducing the heat loss like insulation of boiler ,but still form observation boiler seem most exergy destruction part to which need to improve for 6 mw power plant analysis of exergy indicate that the boiler has exergy destruction at home load $1.1 \mathrm{mw}$ is around $83.35 \%$ and as load increases for highest load 5.6MW the exergy 
destruction found to be $76.33 \%$ thus effiency of $1^{\text {st }}$ law and $2^{\text {nd }}$ law increases with load, we have to work on the peak load for reduce the reversibility. The material capability study and exergy study on various components of boiler can be the scope of the study, with the passage of time and the technology getting matured and new material with higher capacity heat transfer rate like heat pipe and thermo sypon is used, the data designer of the boiler can be redesign the boiler with efficient auxiliary devices

\section{INTEGRATED GASIFICATION COMBINED}

\section{CYCLE}

The integrated gasification combined cycle (IGCC) produces electricity from a solid or liquid fuel. First, the fuel is converted to syngas. Syngas is a mixture of hydrogen and carbon monoxide. Second, the syngas is converted to electricity in a combined cycle power block consisting of a gas turbine process and a steam turbine process which includes a heat recovery steam generator (HRSG). The combined cycle technology is similar to the technology used in modern natural gas fired power plants. Coal based IGCC plants are not commercialized yet. A number of demonstration plants with electric output up to $300 \mathrm{MW}$ have been built in Europe and the US, all with financial support from government. The motivation for pursuing this technology is the potential for better environmental performance at a low marginal cost. This is especially true for mercury removal and $\mathrm{CO}_{2}$ capture. In order to compete with conventional pulverized coal plants under current environmental regulation, the main challenges facing the IGCC technology today are capital cost and availability.

\subsection{IGCC Process Description}

The IGCC is a power generation system that integrates a gasification process with a combined cycle. Coal (or other hydrocarbon fuel such as petroleum coke, biomass) is converted into syngas through the gasification system. The syngas consists mainly of hydrogen (H2) and carbon monoxide (CO).After cleaning; the syngas is used as fuel in the combine cycle to produce electricity generation. The combined cycle is more efficient than conventional powergenerating systems for it re-using waste heat to produce more electricity. The typical flow sheets of an IGCC plant without/with CCS are presented in Fig. 2. This system consists mainly four parts: air separation unit, gasifier, syngas cooling and cleanup processes, and combined cycle.

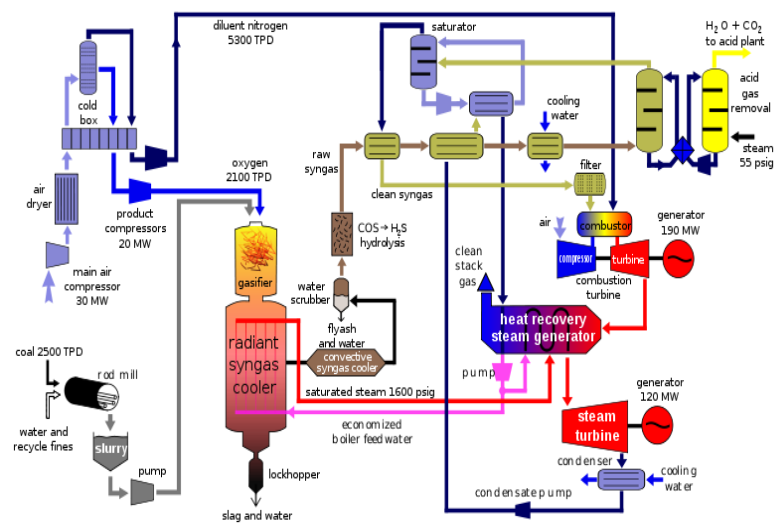

Fig - 2: IGCC Plant block Diagram

\subsection{Advantages of IGCC Technology}

\section{$>\quad$ Higher Fuel Flexibility}

IGCC plants can use any high hydrocarbon fuel, such as low and high-sulfur coal, anthracite, and biomass.

\section{Higher Efficiency}

The electricity generation efficiency of the IGCC process can be higher than $45 \%$ (HHV) withoutCO2 capture. The net efficiency for IGCC in existing plants is around 40-43\% (LHV) and $38-41 \%$ (HHV) without $\mathrm{CO} 2$ capture. With the development of gas turbines, future net efficiency developments should take efficiencies beyond $50 \%$. This is the significant difference between an IGCC and a pulverized coal (PC) power plant.

\section{$>$ Lower Emissions}

IGCC plant is inherently lower emission of SOx, NOx and particulate matter (PM) than conventional coal based power plants: the desulfurization rate is $99 \%$, nitrogen oxide emission is $15-20 \%$ of that of the conventional power plants, as can be seen from Table II, the sulfur dioxide emission of current coal-based IGCC plant in between 10 and 140 $\mathrm{mg} / \mathrm{Nm} 3$ (the Chinese standard is $1200 \mathrm{mg} / \mathrm{Nm} 3$ ). In a coal IGCC plant, the syngas coming out of the gasifier is under high pressure, it does not need to deal with pollutants in a large volume of flue gas. This means the cost of removing pollutants is relatively lower.

\section{$>\quad$ Potential in $\mathrm{CO}_{2}$ Sequestration}

As mentioned above, the syngas from the gasifier is under high pressure. So $\mathrm{CO} 2$ removal IGCC plant requires smaller equipment and simpler process than the conventional coal power station $\mathrm{CO} 2$ removal, such as the post-combustion $\mathrm{CO} 2$ removal. By incorporating a catalyzed water-gas shift reaction in the process, $\mathrm{CO} 2$ can be captured at higher pressure by commercially available technologies, which can be utilized for enhanced oil recovery (EOR) or enhanced coal bed methane recovery (ECMR). 


\section{$>\quad$ Marketable by Products}

During the gasification and gas clean-up process, mineral material (ashes and other inert species) is transformed into slag as a kind of byproduct, which may commercial value in nearby industries. For example, the slag can be used in construction and building applications.

\section{Multiple Products for $\mathrm{H} 2$ and Power}

The flue gas is essentially hydrogen after $\mathrm{CO} 2$ capture, which is gaining popularity as a potential clean-burning fuel source of the future for vehicles and other industries.

\subsection{Disadvantages of IGCC Technology}

Despite there are a lot of advantages about IGCC plant technology, there are some risk that needed to overcome, M.Pe'rez-Fortes present the current challenges in IGCC plants are capital cost and technology availability/ reliability.

\section{$>\quad$ Higher Investment}

Compared to an ultra-supercritical PC plant, an IGCC system required 6-10\% more capital investment.

\section{Lower Reliability}

Although in recent years the availability of IGCC plant technology has increased significantly, it is only about $80 \%$, which is still lagging behind PC plant technology. The reliability is still being considered as one of the most important obstacles. Of course the long construction period and little operating experiences are also the shorting comings of IGCC plant technology.

\subsection{IGCC Technology Current Trends}

\subsubsection{Carbon Dioxide $\left(\mathrm{CO}_{2}\right)$ Capture and Storage}

IGCC plants with $\mathrm{CO}_{2}$ capture gained increased interest in recent years. However, until now there have no applications of $\mathrm{CO}_{2}$ capture at an electric power plant at a large scale (e.g100MW or more), and no IGCC in operation with $\mathrm{CO}_{2}$ capture. Only three large-scale projects have demonstrated in Norway, Canada and Algeria (each storing over one million tons $\mathrm{CO}_{2}$ per year). The biggest obstacle for large-scale application of $\mathrm{CO}_{2}$ Capture and Storage (CCS) with IGCC plant is the loss in electric efficiency, which typically amounts 5-15\%pt. So the application of the $\mathrm{CO}_{2}$ capture process in IGCC plants forms a challenge in pursuit of commercial application of $\mathrm{CO}_{2}$ capture and storage. Studies about the capture $\mathrm{CO}_{2}$ in IGCC power plants can be divided into three stages: conceptual designs, flow sheet modeling and economic assessment based on different technology selections and postulations. Several process models based on current IGCC power plants or ideal IGCC power plants have been developed by various process simulation softwares, such as Aspen Plus ${ }^{\circledR}$, Aspen Hysys $®$ and ECLIPSE. Reference modeled six physical and chemical $\mathrm{CO}_{2}$ absorption process with the IGCC power plant through the Aspen Plus ${ }^{\circledR}$ software. Based on the performance three processes were selected: tow physic processes based on methanol and Sexlexol® solvents and a chemical process using active MDEA.

\subsection{Research and Development Areas}

Here in this section, well discussed areas where current research and development may improve different IGCC components to achieve increased efficiency and reduced costs in future plants and so that it can fulfill the future energy need of the world.

\subsubsection{Gasifier}

Areas where improvements are desired include:

- Feed injector lifetime

- Refractory lifetime or elimination of need for refractory liners

- Thermocouple lifetime

- Coal feed systems

- Slag removal

- Development of a two stage, dry feed gasifier

- Gasifiers suitable for low rank coals

To increase the efficiency of the gasifier, a dry feed system with a second point of feed injection would be desirable. The effect of the second gasification stage is to lower the outlet gas temperature by using thermal energy from the first stage in the endothermic gasification reactions. The principle is also referred to as a "chemical quench" and the effect is increased cold gas efficiency (more chemical energy and less thermal energy in the output). Among the attempts to develop gasifiers which are more suitable for low rank coals, is the KBR Transport gasifier which will be used in Southern Company's future $285 \mathrm{MW}$ Orlando IGCC project in Florida. In 2004, DOE announced a $\$ 235$ million grant to this project. Fluidized bed gasifiers operate at lower temperatures (non-slaging) so that no energy is needed to liquefy the ash. However, there is currently less success with fluidized bed gasifiers than the other types energy is needed to liquefy the ash. However, there is currently less success with fluidized bed gasifiers than the other types of gasifiers. Most experience with these types of gasifiers is with air as the oxidant.

\subsubsection{Air Separation using ITMs}

Both Air Products and Praxair are involved in efforts to develop ionic transport membranes (ITMs) based on ceramic materials which selectively transport oxygen ions when operated at high temperatures $\left(800-900{ }^{\circ} \mathrm{C}\right)$. The ITM would be integrated into the IGCC process be feeding it air from the gas turbine compressor outlet. Studies indicate that application of ITMs could increase IGCC efficiency by $1 \%$-point or more. According to Air Products the cost of air separation could be reduced by about $30 \%$ and the plan is to build the first commercial scale ITM units in 2009. 


\subsubsection{Shift Reaction and $\mathrm{CO}_{2}$ Capture:}

The exothermic shift reaction (or water gas shift reaction) transfers the fuel heating value from $\mathrm{CO}$ to $\mathrm{H}_{2}$ and transfers the carbon from $\mathrm{CO}$ to $\mathrm{CO}_{2}$. The existing method for shift conversion is taking place in two stages at two different temperature levels in the presence of $\mathrm{H}_{2} \mathrm{~S}$. Finally, $\mathrm{H}_{2} \mathrm{~S}$ and $\mathrm{CO}_{2}$ are removed from the syngas in two sequential stages by use of a solvent. As part of the $\mathrm{CO}_{2}$ Capture Project (CCP), development of the so called sorption enhanced water gas shift (SEWGS) process was initiated. In this process, the low temperature shift reactor is replaced with the SEWGS system, which operates as a pressure swing adsorption unit and consists of multiple fixed bed reactors packed with shift catalyst and high temperature $\left(\sim 500{ }^{\circ} \mathrm{C}\right) \mathrm{CO}_{2}$ adsorbent. Regeneration of the adsorbent is accomplished by counter current steam purging. The advantages of the SEWGS process include:

- High conversion of $\mathrm{CO}$ because of simultaneous $\mathrm{CO}_{2}$ removal

- Hydrogen mixture with steam enters the gas turbine at high temperature

The SEWGS system could in principle be applied to a coal based IGCC (not only the studied natural gas scenario), but then the challenge of hot desulfurization and possibly other gas clean up would need to be addressed (see discussion about hot gas clean up) - or else, a significant part of the potential benefit would be lost. Further development regarding the adsorbent performance is required. The CCP project concluded that developing the SEWGS technology was associated with less risk and was more near term than the alternative MWGS concept which will be discussed next. The membrane water gas shift (MWGS) concept is an alternative method to combine the shift reaction and $\mathrm{CO}_{2}$ separation. In principle, this process carries out the shift reaction while at the same time separating out $\mathrm{H}_{2}$ through a membrane. This would happen in a so called membrane reactor, however the CCP concluded that three sequential stages with reaction or separation would involve less risk, e.g. when changing the catalyst. The MWGS have similar advantages to those of the SEWGS regarding high temperature operation. One disadvantage is that recompression of the hydrogen permeate is required. The $\mathrm{CO}_{2}$ stream is available at very high pressure, but may need some treatment to oxidize remaining hydrogen. Also for the MWGS technology, the presence of sulfur and other contaminants in a syngas stream would be a significant challenge. Currently, no sulfur tolerant hydrogen membranes with adequate $\mathrm{H}_{2} / \mathrm{CO}_{2}$ selectivity have been developed. For both the SEWGS and MWGS technologies the potential efficiency improvements are expected to be modest, while the potential reductions in capital costs may be significant as indicated by the CCP study. The application of these technologies in natural gas fired pre-combustion capture plants would be less challenging than in IGCC plants with capture.

\subsubsection{Hot Gas Clean Up (HGCU):}

HGCU processes remove particulates, sulfur compounds and other pollutants at higher temperatures than in the traditional processes such as water scrubbers and acid gas removal systems. The drivers for developing HGCU have been the potential benefits of higher process efficiency ("feeding" the thermal energy of the syngas directly to the gas turbine is more efficient than raising steam is syngas coolers), the elimination of sour water treating and "black mud", and cost reductions. Until the late 1990s, most HGCU programs pursued operating temperatures close to the maximum limit of $1000{ }^{\circ} \mathrm{F}\left(\sim 540^{\circ} \mathrm{C}\right)$ which is compatible with efficient removal of alkali components which would harm the gas turbine. At this temperature alkali vapors condensate on particle surfaces and may therefore be removed in the particle filter. So far, the only HGCU technology which is commercially applicable is particulate removal (candle filters) based on ceramics or sintered metals. For other HGCU processes such as hot desulfurization there has been decreasing interest lately, in part because of disappointing results in finding solid sorbents with the necessary attrition resistance. The capture of mercury and $\mathrm{CO}_{2}$ further complicates the HGCU concept as these components also would need development of HGCU technologies which presently is considered very challenging. Further development of HGCU technologies for removal of components other than particulates is not considered to be very promising.

\subsection{Future Scopes}

Besides the reduction the cost of IGCC plant, the enhancement of the efficiency of the site and the improvement of reliability, $\mathrm{CO} 2$ management is also the main targets to improve the commercialization as control of pollution is most important now a days and competitiveness of IGCC plant technology. For further studies to achieve these targets, several recommendations are divided into two levels:

\subsubsection{Management Level}

Due to the uncertain economic situation and public attention to global warming, some of the IGCC plant construction plants were abandoned. For example, Future Gen IGCC plant cancelled the zero emission plant for "rapidly escalating construction cost".[2] Some IGCC plants with CO2 capture are under development around the world, they will need competent financial support if completely successfully. So policy-makers should have clear understanding of the importance of CCS on the development of IGCC plant technology 


\subsubsection{Technological Level}

Recent studies on IGCC plant with $\mathrm{CO} 2$ capture focus on the cost and performance which based on technical and economic assumptions. These results could provide useful references for the future operation of $\mathrm{CO} 2$ capture with IGCC plant. Simulation optimization of the flow sheet and units can be considered for overall performance improved for new IGCC plant with $\mathrm{CO} 2$ capture. Various separation technologies for $\mathrm{CO} 2$ capture should be investigated since the improvements of $\mathrm{CO} 2$ capture technology could make IGCC plant more competitive compared to other types of power plant. Substituting CO2 for N2 as a coal transport gas in dry-feed gasifier could improves hydrogen production from the gasifier. To gain an operational experience, construction of an IGCC plant with $\mathrm{CO} 2$ demonstration plant should be built quickly as a basic for further development.

\section{CONCLUSIONS}

Exergy analysis is shown in this paper to be able to help understand the performance of coal fired, gas fired combined cycle thermal power plants and identify design possible efficiency improvements. It gives logical solution improving the power production opportunities in thermal power plants. By the exergy analysis we can conclude that main energy loss in boiler in coal based thermal power plant and combustion chamber in gas fired combined cycle thermal power plant. Of course, in every plant component such as a boiler, combustion chamber there is some intrinsic irreversibility which cannot, owing to the present state of technological development, be eliminated. In addition, exergy methods are useful in assessing which improvements are worthwhile, and should be used along with other pertinent information to guide efficiency improvement efforts for steam power plants. Of course, Efficiency of some plant components is improved by increasing their size. For example, heat exchangers of a given design perform better when the heat transfer areas are increased. However, this involves extra cost and hence there is a limiting size beyond which further increase would not be justified economically. Exergy analysis was undertaken at the thermal power plant which highlighted the areas that could be addressed to improve the efficiency. A recommendation of retrofitting and replacement was done for the system. On going work in development of intelligent power plant is expected to improve stability of steam headers, responsiveness to steam demand, increase power generation flexibility, minimize operations cost, improve overall plant efficiency, increase fuel cost savings and reduce $\mathrm{CO} 2$ Emission.

In India the existing thermal power plants are not working with good efficiency, even though they are of higher capacity most of them fail to achieve good efficiency. IGCC plant technology is a very recent innovation and it is only installed in 5 places. The leading country China has found the importance of IGCC plant and lots of researches are going on in the same. For developing countries like India it is the most suitable option if we think in the future prospective. And the present plants produces so much of pollution where as IGCC method is environmental friendly, so lots of researches should be taken up from the engineering point of view on this.

\section{REFERENCES}

[1]. Datta A, Sengupta S, Duttagupta S. Exergy analysis of a coal-based 210MW thermal power plant. International Journal of Energy Research 2007; 31:14- 28

[2]. Som SK, Mondal SS, Dash SK. Energy and exergy balance in the process of pulverized coal combustion in a tubular combustor. Journal of Heat Transfer, Transactions of the ASME 2005; 127: 1322-33.

[3]. Ganguly R, Ray TK, Datta A, Gupta A. Exergy-based performance analysis for proper O\&M decisions in a steam power plant. Energy Conversion and Man- agement 2010; 51: 1333-44

[4]. S.K. Som, A. Datta, Thermodynamic irreversibilities and exergy balance in combustion processes, Progress in Energy and Combustion Science 34 (2008) 351-376

[5]. Datta A, Som SK. Energy and exergy balance in a gas turbine combustor. J Power Energy-Proc Inst Mech Eng $1999 ; 213: 23-32$

[6]. A. Yunus and A. Michael, "Thermodynamics an Engineering Approach," Tata McGraw Hill, New Delhi, 2007. [7]. Chao Huang, Liuwen Su, Siqi He, Hong Lin, Haoyang Liu , "Potential Research on Energy Conservation and Emission Reduction of IGCC Technology in the Power Industry," International Journal of Energy Science (IJES) Volume 3 Issue 3, June 2013 , pp 175-179 